BMJ Paediatrics Open

\title{
Reaching the paediatric chest pain audience outside of ambulatory clinic using internet-based education
}

\author{
Adam W Powell (1) , ${ }^{1,2}$ Zachary Ritzenthaler, ${ }^{3}$ Katherine W Powell, ${ }^{4}$
} Rachel Camper, ${ }^{2}$ Nicholas L Madsen ${ }^{1,2}$

To cite: Powell AW, Ritzenthaler Z, Powell KW, et al. Reaching the paediatric chest pain audience outside of ambulatory clinic using internet-based education. BMJ Paediatrics Open 2020;4:e000778. doi:10.1136/ bmjpo-2020-000778

Received 24 June 2020 Accepted 27 August 2020
Check for updates

(c) Author(s) (or their employer(s)) 2020. Re-use permitted under CC BY-NC. No commercial re-use. See rights and permissions. Published by BMJ.

${ }^{1}$ Department of Pediatrics, University of Cincinnati College of Medicine, Cincinnati, $\mathrm{OH}$, USA ${ }^{2}$ The Heart Institute, Cincinnati Children's Hospital Medical Center, Cincinnati, OH, USA ${ }^{3}$ Undergraduate Studies, University of Cincinnati, Cincinnati, OH, USA ${ }^{4}$ Department of Emergency Medicine, Cincinnati Children's Hospital Medical Center Cincinnati, $\mathrm{OH}$, USA

Correspondence to Dr Adam W Powell; adam. powell@cchmc.org

\section{ABSTRACT}

Paediatric chest pain is common, yet there remain significant barriers to educating and reassuring patients and their families. In July 2014, a blog titled 6 Questions to Ask When Your Child Complains of Chest Pain was posted to the Cincinnati Children's Hospital Medical Center website to help educate children and parents about paediatric chest pain. The enhanced interactions through internet-based resources create the opportunity to address chest pain in a way that both educate and provide reassurance. Through the reassurance, there is the potential to meaningfully reduce patient stress all while also decreasing medical costs and potential medical visits.

Paediatric chest pain is rarely cardiac, and yet, patient and family emotional distress is often quite high. ${ }^{12}$ Unfortunately, many barriers exist regarding effective physician and patient/parent communication, which may lead to a failure to provide effective reassurance. ${ }^{3}$ Patients and their parents commonly seek in-person professional medical advice but may be met with decreased clinic availability, prolonged emergency room waits, potential infectious exposures and expensive, often unnecessary medical tests. In light of these factors and the increasing accessibility of technology, the internet has become a common source of information. ${ }^{4}$

In July 2014, a blog titled 6 Questions to Ask When Your Child Complains of Chest Pain ${ }^{5}$ was posted to the Cincinnati Children's Hospital Medical Center (CCHMC) website to help educate children and parents about paediatric chest pain. Since that original posting, the blog has been widely read reaching over 1.1 million international viewers (figure 1) becoming the most-viewed CCHMC blog and a frequently visited paediatric chest pain resource on Google. In addition to its originally intended resource of guidance regarding the possible aetiology of the reader's chest pain, the reader may post a question or comment and ultimately receive a reply from one of the blog's authorship team.
Comments from July 2014 to September 2019 were collected and analysed to provide clues into who was benefiting from this unintended throughway. Duplicate comments were excluded and country of origin was elicited by the CCHMC analytics team.

Details on the comments left are presented in table 1 . Interestingly, $26.5 \%$ of individuals had interacted with a healthcare provider before their comment/question on the blog, meaning they were not adequately reassured by their medical team. This likely speaks to the various barriers for adequate patient education in the clinic visit, which include communication, psychosocial and educational. ${ }^{3}$ On the other hand, $75 \%$ of respondents did so before being seen by their medical team. While we do not know how many of these persons ultimately saw a physician, reducing the number of unnecessary visits could result in significant savings. While the chief motivation for producing high-quality internetbased educational materials is to decrease patient and parent anxiety, the potential cost savings are quite noteworthy and represent a very advantageous secondary outcome as hospitals work to decrease overall medical expenditure.

Another interesting observation from our blog experience is that while $\sim 66 \%$ of comments were from parents or other adult contacts, the remainder came directly from the individual with chest pain. This speaks to the importance of ensuring that the materials we provide are accessible, age appropriate, developed with attention to the needs of health literacy and sourced effectively for technologically savvy paediatric patients. Other studies have shown significant successes targeting this group for education, ${ }^{6}$ yet we often overlook them in favour of parental information. Obviously, the potential issues of the child not disclosing their symptoms to their parent should be heeded; in fact, there may even be a unique opportunity to use this 


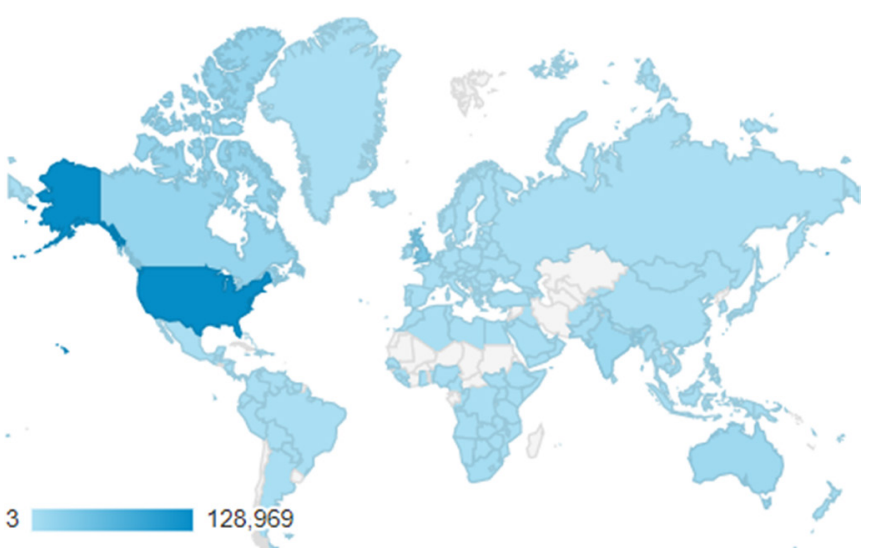

Figure 1 Map showing the global distribution of visitors to the Cincinnati Children's Hospital blog titled 6 Questions to Ask When Your Child Complains of Chest Pain. Darker shades of blue indicate larger number of visitors.

medium to direct children/adolescents to their parents with a symptom of concern.

In conclusion, enhanced interactions through internetbased resources create the opportunity to address paediatric chest pain in a way that both educates and provides reassurance. Through the reassurance, there may be positive secondary outcomes such as decreasing medical costs and reducing potential infectious exposures. Information directed to the internet-savvy patient should not

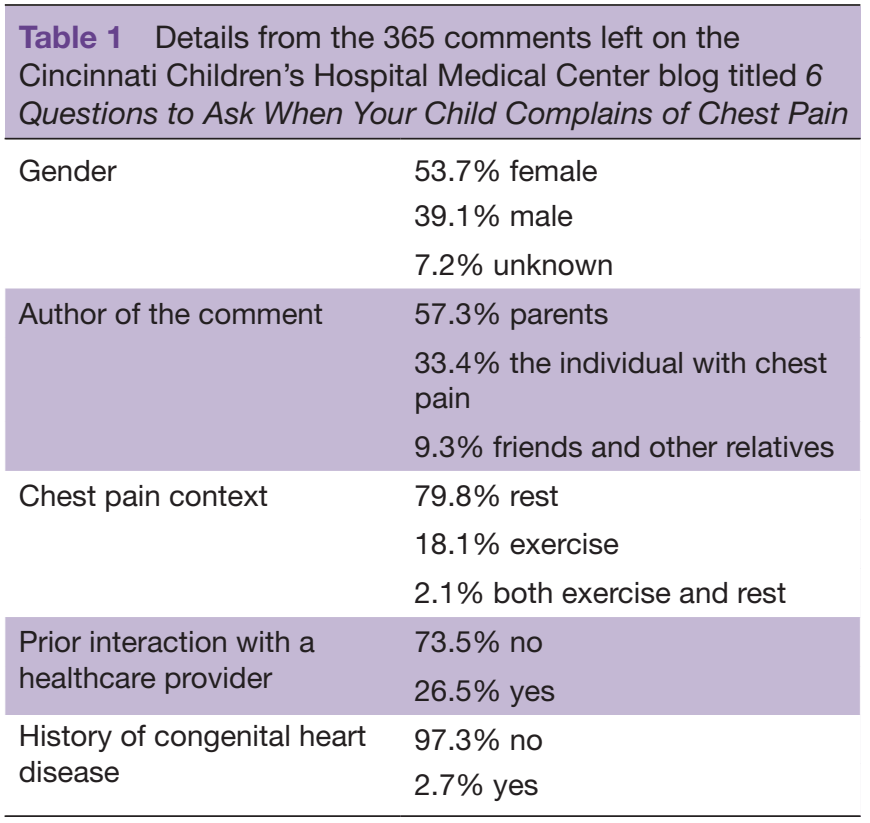

be limited to parent information as paediatric patients often perform their own symptom research. We believe that these lessons and learnings are not exclusive to paediatric chest pain, but rather provide an example that other symptom-based, or condition-based, patient and parent facing resources may wish to emulate.

Contributors AWP and NLM conceptualised and designed the study, drafted the initial manuscript and reviewed and revised the manuscript. ZR collected data, carried out the initial analysis and reviewed and revised the manuscript. KWP assisted in the manuscript conceptualisation and critically reviewed the manuscript for important intellectual content. RC collected data, carried out subsequent data analysis and reviewed and revised the manuscript. All authors approved the final manuscript as submitted and agree to be accountable for all aspects of the work.

Funding The authors have not declared a specific grant for this research from any funding agency in the public, commercial or not-for-profit sectors.

Map disclaimer The depiction of boundaries on this map does not imply the expression of any opinion whatsoever on the part of BMJ (or any member of its group) concerning the legal status of any country, territory, jurisdiction or area or of its authorities. This map is provided without any warranty of any kind, either express or implied.

Competing interests None declared.

Patient and public involvement Patients and/or the public were not involved in the design, or conduct, or reporting or dissemination plans of this research.

Patient consent for publication Not required.

Provenance and peer review Not commissioned; externally peer reviewed.

Open access This is an open access article distributed in accordance with the Creative Commons Attribution Non Commercial (CC BY-NC 4.0) license, which permits others to distribute, remix, adapt, build upon this work non-commercially, and license their derivative works on different terms, provided the original work is properly cited, appropriate credit is given, any changes made indicated, and the use is non-commercial. See: http://creativecommons.org/licenses/by-nc/4.0/.

ORCID iD

Adam W Powell http://orcid.org/0000-0002-5537-032X

\section{REFERENCES}

1 Moran B, Bryan S, Farrar T, et al. Diagnostic evaluation of nontraumatic chest pain in athletes. Curr Sports Med Rep 2017; 16:84-94.

2 Kane DA, Fulton DR, Saleeb S, et al. Needles in hay: chest pain as the presenting symptom in children with serious underlying cardiac pathology. Congenit Heart Dis 2010;5:366-73.

3 Sarkar U, Schillinger D, Bibbins-Domingo K, et al. Patient-physicians' information exchange in outpatient cardiac care: time for a heart to heart? Patient Educ Couns 2011;85:173-9.

4 Coomes EA, Haghbayan H, Finken LR, et al. Information on cardiovascular disease in the digital era: results from a cross-sectional patient survey. Can J Cardiol 2019;35:791-4.

5 Madsen NL. Six questions to ask when your child complains of chest pain. Cincinnati Children's Hospital Medical Center, 2014. Available: https://blog.cincinnatichildrens.org/healthy-living/6-questions-toask-when-your-child-complains-of-chest-pain [Accessed 21 Feb 2020].

6 Gray NJ, Klein JD, Noyce PR, et al. Health information-seeking behaviour in adolescence: the place of the Internet. Soc Sci Med 2005;60:1467-78. 